Frontiers in Heat Pipes

\title{
NUMERICAL SIMULATION ON FLOW AND HEAT TRANSFER IN OSCILLATING HEAT PIPES
}

\author{
S.F. Wang, ${ }^{\mathrm{a}, *}$, Z.R. Lin ${ }^{\mathrm{a}}$, Z.Y. Lee ${ }^{\mathrm{b}}$, and L.W. Zhang ${ }^{\mathrm{b}}$ \\ ${ }^{a}$ Key Laboratory of Enhanced Heat Transfer and Energy Conservation of the Ministry of Education, \\ South China University of Technology, Guangzhou City, Guangdong Province, 510640, China \\ ${ }^{b}$ Novark Technology Inc, Shenzhen City, Guangdong Province, 518172, China
}

\begin{abstract}
In order to predict the heat transport capability of oscillating heat pipes (OHPs), a mathematical and physical model of OHP was built to simulate the process of flow and heat transfer in vertical bottom heating mode. Water was used as working fluid. Mixture model in FLUENT was used for twophase flow numerical simulation. The result showed that the numerical simulation was successful to reproduce the behavior of the internal flow of OHP, including vapor generation in evaporation section, oscillation phenomena caused by the pressure difference and heat transfer due to oscillation. Comparing with the experimental tests, the simulation results agreed with the experimental records fairly well.
\end{abstract}

Keywords: oscillating heat pipes (OHPs), numerical simulation, heat transfer, flow, predicting correlation

\section{INTRODUCTION}

An oscillating heat pipe (OHP) is a two-phase flow device used for transferring heat without any moving mechanical parts (Akachi and Polášek, 1996; Polášek and Zelko, 1997). It consists of tubes/channels of capillary dimensions arranged in a serpentine manner and joined end to end as shown in Fig.1. It is predicted as one of the most promising solution for higher heat dissipation compact cooling. The heat transfer characteristics of OHPs have become a hot research. However, most studies focused on the experimental investigations. Only a few researches paid attention to the numerical simulations. Zuo (Zuo et al., 2001) simulated the operation of vapor and liquid slugs in OHP by the single spring-mass-damper system, which was far away from the experimental results. Wong (Wong et al., 1999) predicted the direction of vapor and liquid slugs by the multiple spring-mass-damper system, but without considering the effect of heat exchange. Dobson (Dobson, 2004) and Faghri et al. (Shafii et al., 2002; Zhang et al., 2002) established the mass, momentum and energy conservation equations of OHP by the control volume method. Khandekar (Khandekar et al., 2002) proposed an artificial neutral network to predict the thermal performance of OHP, which based on an amount of experimental data. In fact, there was still no an effective numerical simulation to predict the thermal performance of OHPs successfully.

With the aim of exploring potential applications of OHP technology, it is very important to predict the thermal performance of OHP by the numerical simulation, rather than by a large number of experiments. In this work, a mathematical and physical model of OHP was built to simulate the process of flow and heat transfer. The simulation results were compared with the experimental results.

\section{EXPERIMENTAL APPARATUS AND PROCEDURE}

In the experiments, an experimental apparatus of OHPs were established for thermal performance test to study the flow and heat transfer. The four-turn OHP was selected as a typical shape. Pure water was used as working fluid. The operational orientation was vertical bottom heating mode.

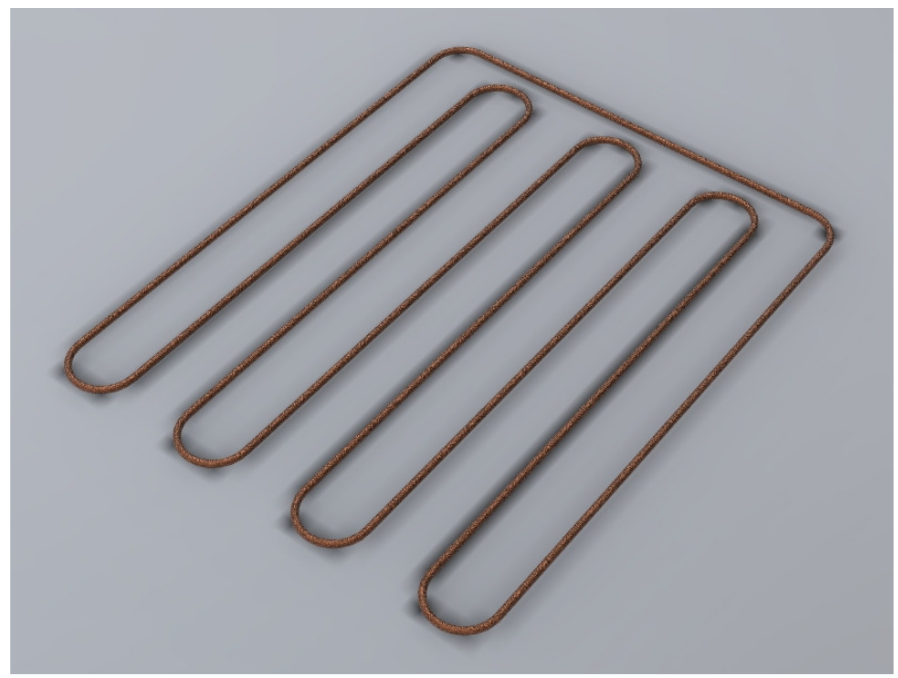

Fig. 1 Prototype of OHP

In the thermal performance test, two types of copper tubes with outer diameter $\left(D_{o}\right)$ of 2.5 and $3 \mathrm{~mm}$, inner diameter $\left(D_{i}\right)$ of 1.3 and $1.8 \mathrm{~mm}$ were used as manufacturing material to be bent into the OHPs respectively. The heat transfer length $(L)$ of $200 \mathrm{~mm}$ were adopted for comparative experiments. In the liquid filling process, internal channels of copper tubes were first exhausted and the working fluid was filled fully into the tube under the pressure difference. Liquid filling ratio was controlled around $50 \pm 5 \%$ by the second vacuum, which discharged the excess liquid. The experimental apparatus of OHPs was shown in Fig. 2. The nickel chrome electric wires were wound around the copper tube,

Corresponding author.E-mail: sfwang@scut.edu.cn 
which was wrapped in thermal insulation adhesive plaster, as evaporation section. They were connected to the transformer, which supplied heating power by adjusting the current and voltage. The length of evaporation section was $20 \mathrm{~mm}$, the same as the condensation section; and the condensation section was cooled by water $\left(25 \pm 0.05^{\circ} \mathrm{C}\right)$. The OMEGA K-type thermocouples were installed to measure the wall temperature at different positions of OHPs. The detailed location of thermocouples was shown in Fig. 2.The pulse of temperature was measured to reflect the internal working fluid oscillation indirectly.

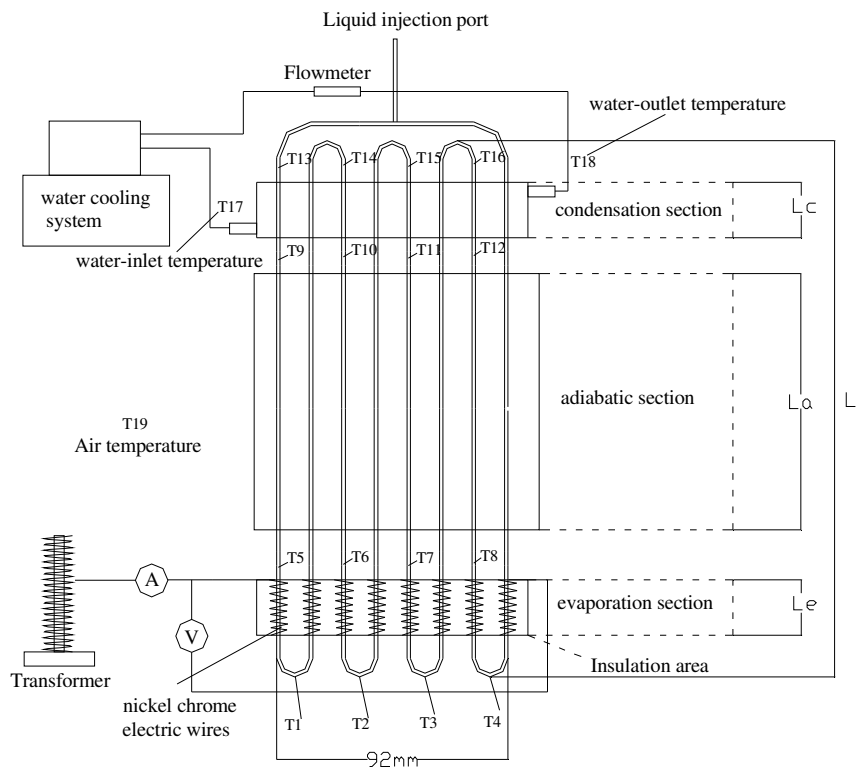

Lc: the length of condensation section; La: the length of adiabatic section; Le: the length of evaporation section;

Fig. 2 Experimental apparatus of OHPs

All tests were conducted at an ambient temperature of $25 \pm 1^{\circ} \mathrm{C}$. Base on the application requirements, when the average temperature of evaporation section was over $100^{\circ} \mathrm{C}$, the experiment would be stopped. The thermal resistance of OHPs was equal to temperature difference between condensation section and evaporation section divided by heating power. $R_{O H P}=\left(T_{e}-T_{c}\right) / Q_{h}\left(R_{O H P}\right.$ : thermal resistance of OHP; $T_{e}$ : average temperature of $T_{1}, T_{2}, T_{3}$ and $T_{4}$ approximately instead of evaporation section; $T_{c}$ : average temperature of $T_{13}, T_{14}, T_{15}$ and $T_{16}$ approximately instead of condensation section; $Q_{h}$ : heating power).

\section{DESCRIPTION OF SIMULATION}

\subsection{Physical model}

The 2D physical model was built to simulate the internal flow and heat transfer in OHPs, shown in Fig.3. Pure water was used as working fluid. The internal flow of OHP was mainly vapor-liquid two phase flow. It was assumed that the density of liquid phase was incompressible, and the vapor phase was compressible. The phase and density changed with the temperature changed. The geometric model and mesh diagram were shown in Fig.3. The design length of evaporation section was $20 \mathrm{~mm}$, and the length of condensation section was $20 \mathrm{~mm}$.

\subsection{Definite conditions}

As the OHP was operated in a negative pressure, we assumed that the water vaporization temperature is $50^{\circ} \mathrm{C}$ accord to the experimental condition. It meant that the liquid phase of working fluid evaporated over $50^{\circ} \mathrm{C}$ and the vapor phase condensed below $50^{\circ} \mathrm{C}$. The heat flux in evaporation section depended on the power input. The heat transfer coefficient in condensation section was set according to the actual situation. The insulation section was set to insulation boundary condition.

In the cases, mixture model was used for flow and heat transfer simulation. The user defined function was added to calculate mass and energy transport, in order to achieve heat transfer process of evaporation and condensation.
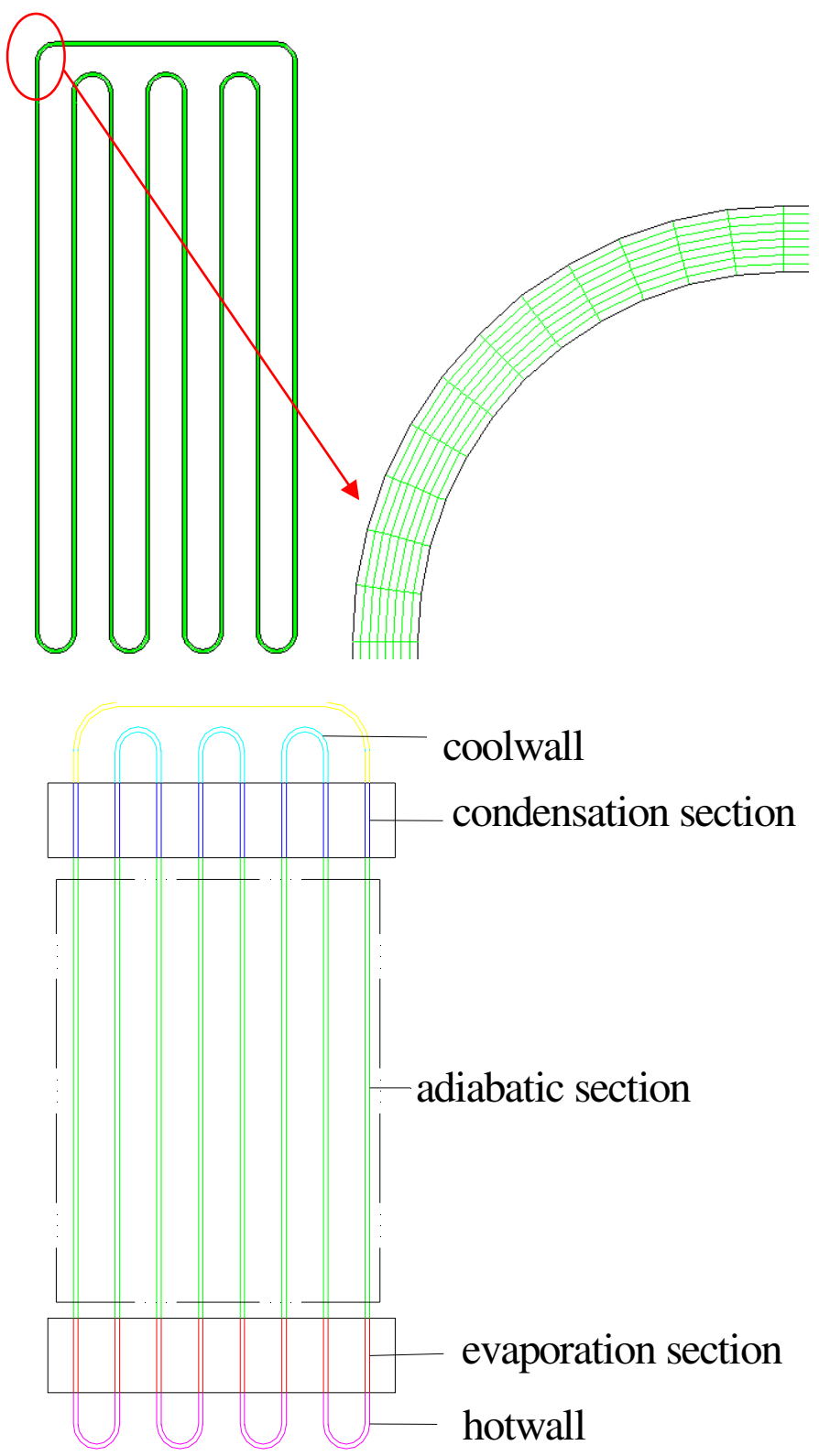

Fig. 3 Geometric model and mesh diagram

\section{SIMULATION ON START-UP PROCESS}

In the simulation case, the four-turn OHP with inner diameter $\left(D_{i}\right)$ of 1.3 and heat transfer length of $200 \mathrm{~mm}$ was selected as 2D model for comparison. The heating power was $24 \mathrm{~W}$. As shown in Fig.4, the startup of OHP had been recorded, which went through the process of heat transfer. From $1 \mathrm{~s}$ to $5 \mathrm{~s}$, the temperature in evaporation section increased due to power input. When the time up to $7 \mathrm{~s}$, the evaporation section reached a certain temperature, the generation of bubbles began. The region of high temperature in evaporation section was expanding from $7 \mathrm{~s}$ to $9 \mathrm{~s}$. As the temperature increased, the bubbles jetted across the evaporation section to the condensation section. High temperature 


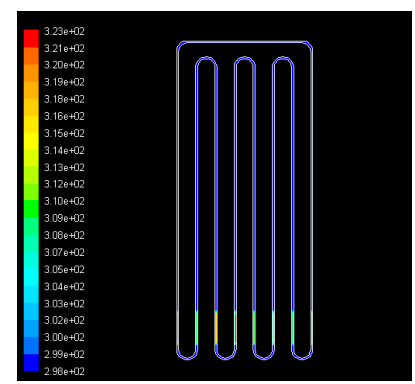

$1 \mathrm{~s}$

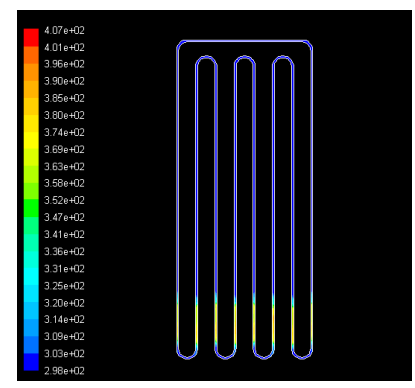

$7 \mathrm{~s}$

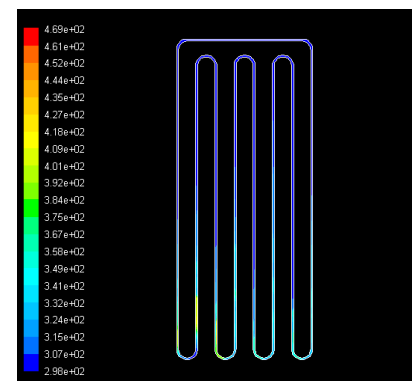

$9 \mathrm{~s}$

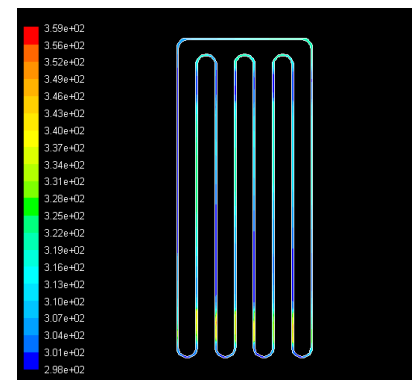

$13 \mathrm{~s}$

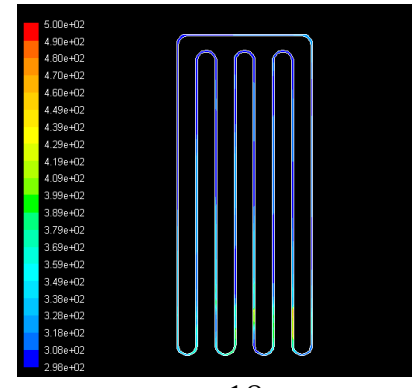

$18 \mathrm{~s}$

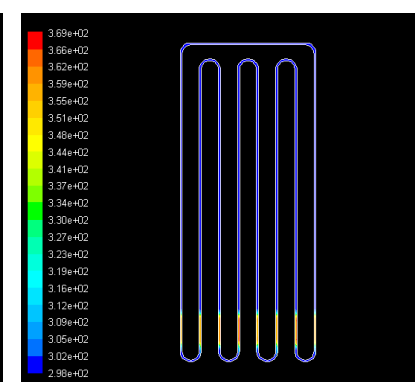

$5 \mathrm{~s}$

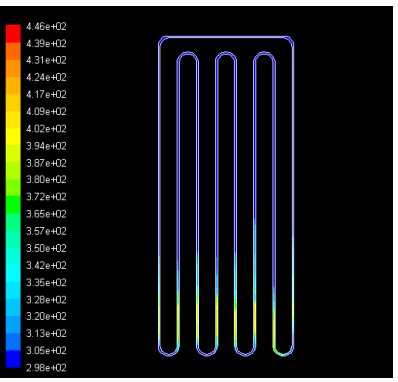

$8 \mathrm{~s}$

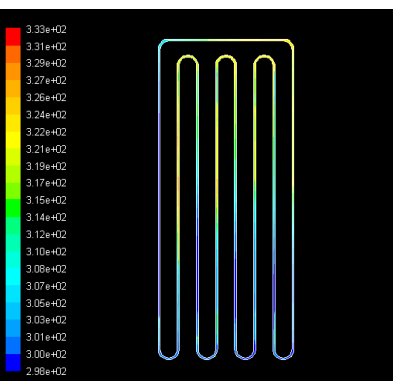

$10 \mathrm{~s}$

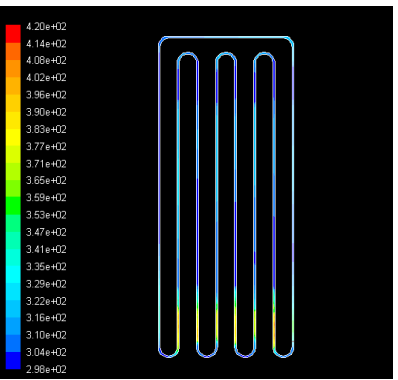

$17 \mathrm{~s}$

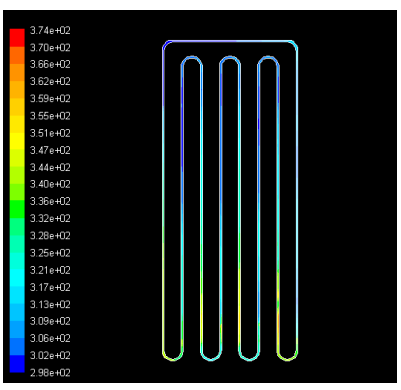

$20 \mathrm{~s}$
Fig. 4 Contours of temperature change in OHP start-up process

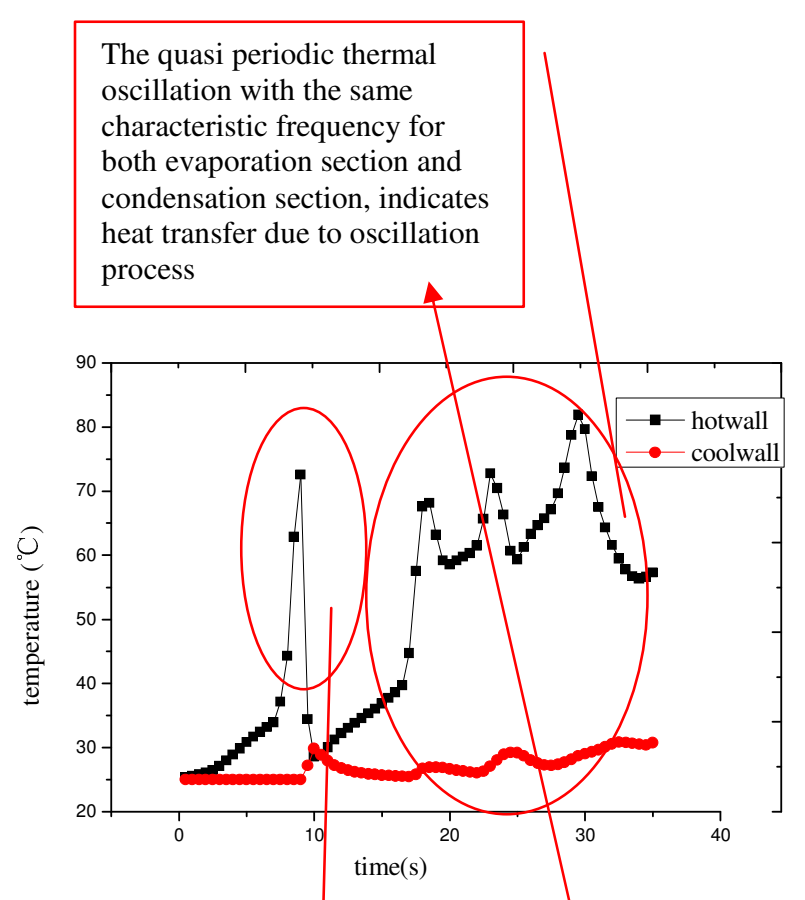

Fig. 5 Temperature monitors record for DHP startup process simulation (heating power $=24 \mathrm{~W}$ )

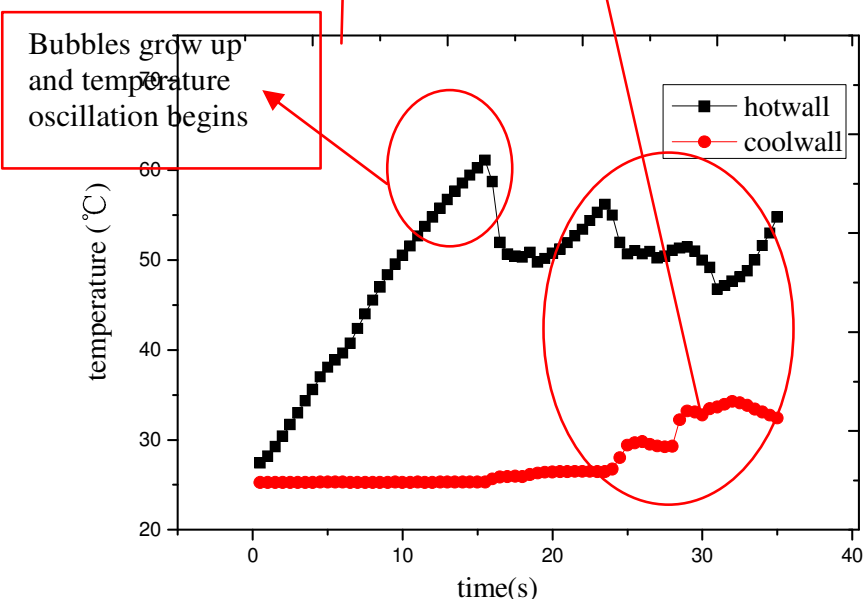

Fig. 6 Temperature record for OHP startup test (heating power=24W)

appeared in the condensation section, while the evaporation section was cooled down in 10s. After that, the vapor slugs (bubbles) and liquid slugs (the liquid region between bubbles) oscillation occurred and made the heat transfer from evaporation section to condensation section. The temperature distribution of OHP became uniform. In 13s, vapor slugs (bubbles) condensed into liquid in the condensation section. With the help of gravity and capillary forces, the condensed liquid returned back to the evaporation section. At the same time, the temperature in evaporation section increased from $10 \mathrm{~s}$ to $17 \mathrm{~s}$, which reserved energy for the next oscillation cycle. In $18 \mathrm{~s}$ to 20 s, the new cycle began. The evaporation section received the energy and reached a certain temperature. The condensed liquid evaporated and generated the bubbles again. As a result, the heat transfer process of OHP mainly depended on this vapor and liquid slug oscillation, which occurred due to pressure difference between evaporation and condensation.

Therefore, the numerical simulation was successful to reproduce the startup process of OHP, including vapor generation in evaporation section, oscillation phenomena caused by the pressure difference and heat transfer due to oscillation process. They matched with the experimental observation. As shown in Fig.5, the temperature change in 
OHP startup process (the total time is 35 seconds) was recorded. It was found that when the hotwall (marked in Fig.3) reaches a certain temperature (about $75^{\circ} \mathrm{C}$ ), the temperature oscillation began. The oscillation amplitude and temperature difference between evaporation and condensation section was decreasing with the startup of OHP. The quasi periodic thermal oscillation with the same characteristic frequency appeared in both evaporation section and condensation section, which indicated heat transfer due to oscillation process. Comparing to the experimental records in Fig.6, the trend of temperature change in simulation was consistent with experimental results.

\section{NUMERICAL SIMULATION COMPARED WITH EXPERIMENTAL RESULTS}

\subsection{Comparison of temperature curves}

In the case, the OHP with inner diameter of $1.3 \mathrm{~mm}$ and heat transfer length of $200 \mathrm{~mm}$ was selected for comparison between simulation and experimental results. Fig.7 was the temperature record for OHP performance test in $24 \mathrm{~W}$; while Fig. 8 was the temperature record for OHP 2D simulations in 24W. As can been seen in Fig.8, the oscillation range in temperature was consistent with the experimental record. The average temperature of the experimental record in evaporation section was about $57^{\circ} \mathrm{C}$; while condensation section's was about $32^{\circ} \mathrm{C}$. The average temperature of $2 \mathrm{D}$ simulation record in evaporation section was about $63^{\circ} \mathrm{C}$; while condensation section's was about $28^{\circ} \mathrm{C}$.

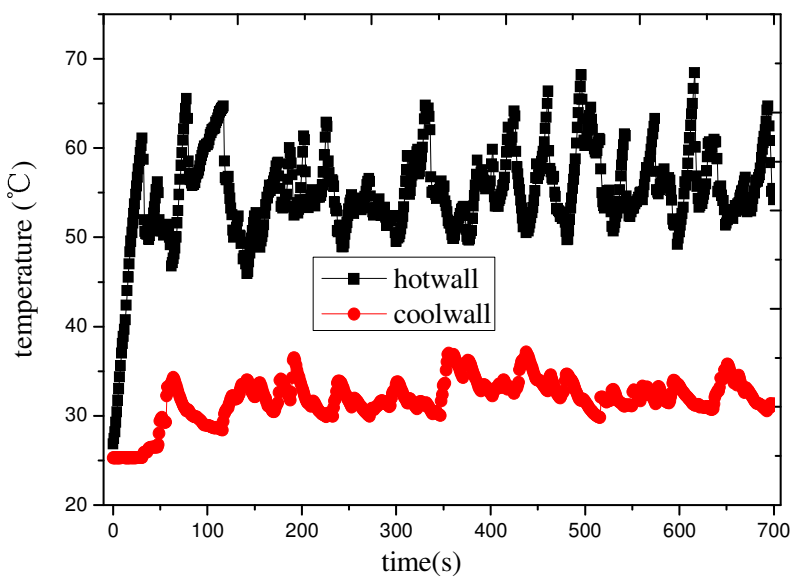

Fig. 7 Temperature record for OHP performance test in $24 \mathrm{~W}$ $\left(D_{i}=1.3 \mathrm{~mm}, D_{o}=2.5 \mathrm{~mm}, L=200 \mathrm{~mm}\right)$

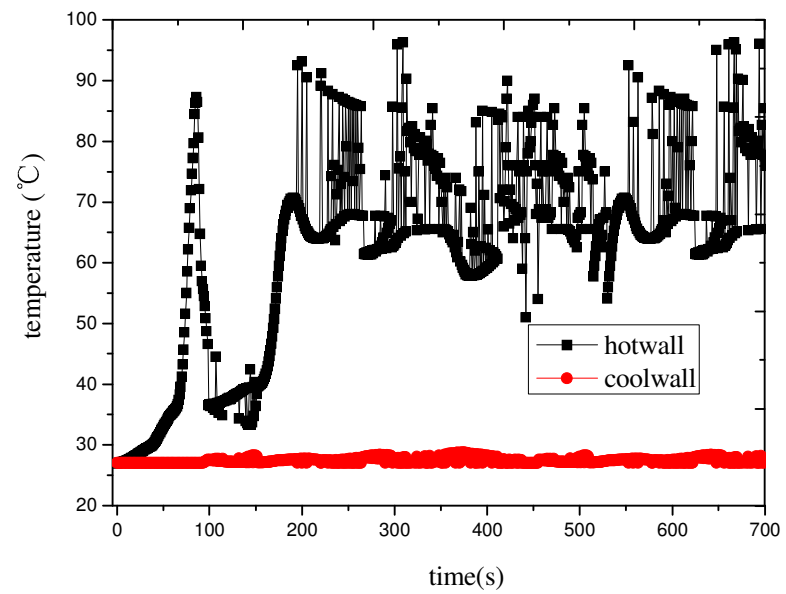

Fig. 8 Temperature record for OHP 2D simulation in 24W $\left(D_{i}=1.3 \mathrm{~mm}, D_{o}=2.5 \mathrm{~mm}, L=200 \mathrm{~mm}\right)$
The simulation temperature was slightly higher than the experimental record, but it represented the simulation model was successful to predict the OHP performance and operation. Furthermore, it was noticed that the simulation record needed some time to develop into the stable oscillation state after the startup process. In contrast, the experimental record reached the stable oscillation state earlier. Therefore, the longer simulation, the more accurate results can be obtained, closer to the real operation.

\subsection{Comparison of thermal resistance}

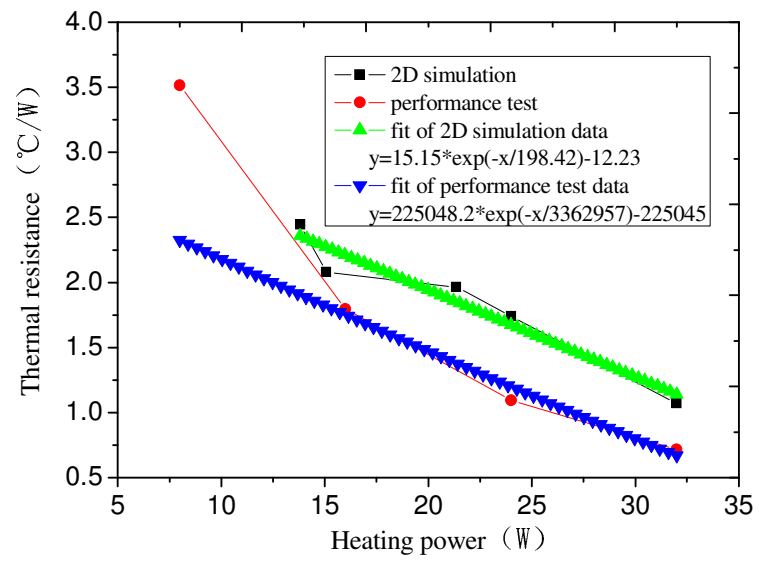

(a) $D_{i}=1.3 \mathrm{~mm}, D_{o}=2.5 \mathrm{~mm}, L=200 \mathrm{~mm}$

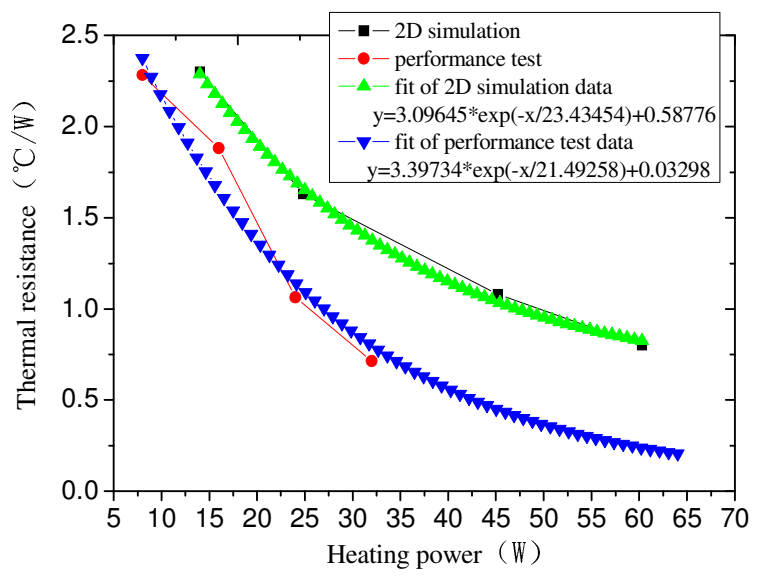

(b) $D_{i}=1.8 \mathrm{~mm}, D_{o}=3 \mathrm{~mm}, L=200 \mathrm{~mm}$

Fig. 9 Comparison of thermal resistance among 2D simulation and performance test

After the section discussed above, it proved that 2D mathematical model could successfully simulate the internal flow of an OHP. In this section, several cases with different parameters were selected for comparison in different operating conditions. As can be seen in Fig.9, the thermal resistance of 2D model simulation was higher than the test data. From the comparison of fitting equations between 2D simulation and performance tests, the gap kept stable. This may be due to the condition difference between the calculations and experiments.

In conclusion, it was believed that 2D model was considered as the good solution for OHP simulation. In order to fix the error of the simulation results, a fitting formula to consider the design parameters of OHP need to create for predicting the thermal performance of OHPs. 


\subsection{Correlation prediction of OHPs}

For reducing the error of the simulation results, it needed a fitting formula to fix the gap between the simulation and the performance test. Considering the past prediction method mentioned by Khandekar (Khandekar et al., 2003), Katpradit (Katpradit et al., 2005), Charoensawan (Charoensawan et al., 2007), Arslan and Ozdemir (Arslan and Ozdemir, 2008), Sakulchangsatjatai (Sakulchangsatjatai et al., 2004), the dominating dimensionless parameters, including $D_{i} / L$, $J a, B o$ and $1+\left(\rho_{v} / \rho_{l}\right)^{0.25}$, and some operating parameters including $\Delta T, Q$ were used to fix a correlation for predicting the heat transport capability of OHPs.

$D_{i} / L$ is the ratio of the inner diameter to that of the heat transfer length of the tube and it represents the geometry of the OHPs. The jakob number $\left(J a=C_{p} \Delta T / h_{f g}\right)$ is the ratio of sensible heat to that of the latent heat of the working fluid. The bond number $\left(B o=D_{i}\left[g\left(\rho_{l}-\rho_{v}\right) / \sigma\right]^{0.5}\right)$ is the ratio of the buoyancy force to that of the surface tension force of the working fluid. The Wallis number $\left(W a=1+\left(\rho_{v} / \rho_{l}\right)^{0.25}\right)$ can be used to explain the flooding phenomenon that influences dry-out to occur at the evaporation section. $\Delta T$ is the temperature difference between evaporation section and condensation section from the simulation results. $Q$ is the power input.

According to the dimensionless method, the 2D simulation prediction of thermal resistance in vertical bottom heating mode was:

$R_{2 D}=0.02669 \times \Delta T^{1.28803} \times Q^{-1.28803} \times[D i / L]^{-0.72677} \times\left[C p \Delta T / h_{f g}\right]^{-0.57583} \times\left[D i\left[g\left(\rho_{l}-\rho_{v}\right) / \sigma\right]^{0.5}\right]^{0.501}$

$\times\left[1+\left(p_{v} / p_{l}\right)^{0.25}\right]^{-11.66237}$

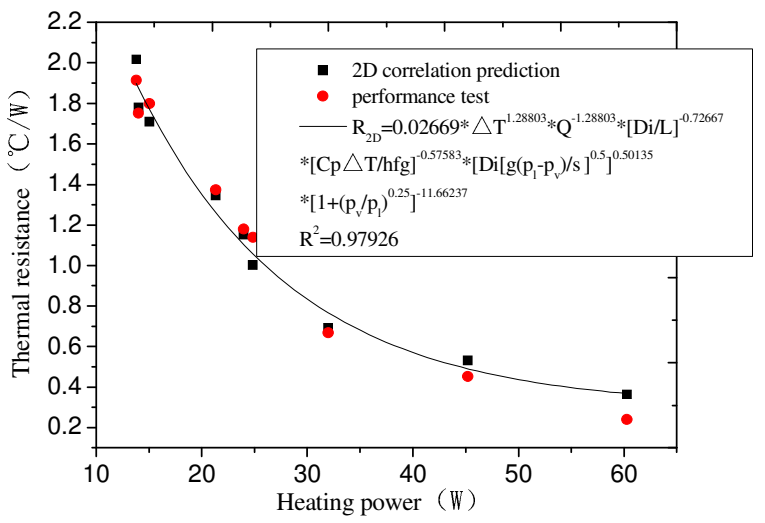

Fig. 10 Comparison of measurement and prediction

As can be seen in Fig.10, R-square of 2D simulation prediction was 0.98175 , which represents high reliability for the prediction fitting formula. The correlation prediction agrees with the experimental results fairly well. In conclusion, the operation of OHPs can be predicted by inner diameter, heat transfer length, heating power input and temperature difference required. Instead, OHPs can be designed according to the actual conditions.

\section{CONCLUSIONS}

In order to predict the heat transport capability of OHPs, a mathematical and physical model of OHP was built to simulate the internal flow and heat transfer in vertical bottom heating mode. Water was used as working fluid. Mixture model in FLUENT was used for two-phase flow numerical simulation. Conclusions of the studies can be summarized as follows:

(1) The numerical simulation was successful to reproduce the startup process of OHP, including vapor generation in evaporation section, oscillation phenomena caused by the pressure difference and heat transfer due to oscillation. The quasi periodic thermal oscillation with the same characteristic frequency for evaporation section and condensation section, indicated heat transfer phenomenon between these two sections. Comparing with the experimental observations, the simulation results agreed with the experimental results fairly well.

(2) According to the comparison of temperature curves record and thermal resistance between 2D model and performance tests, it was found that mixture model was successful to simulate the OHP operation, which more consistent with the experimental data.

(3) In order to reduce the error of the simulation results, the dimensionless method was used to create a fitting formula to fix the gap between the simulation and the performance test. The simulation correlation could predict the heat transport capability of OHPs successfully.

The 2D simulation prediction of thermal resistance in vertical bottom heating mode was:

$R_{2 D}=0.02669 \times \Delta T^{1.28803} \times Q^{-1.28803} \times[D i / L]^{0.72677} \times\left[C p \Delta T / h_{f g}\right]^{0.57583} \times\left[D i\left[g\left(\rho_{l}-\rho_{v}\right) / \sigma\right]^{0.5}\right]^{0.50135}$ $\times\left[1+\left(p_{v} / p_{l}\right)^{0.25}\right]^{-11.66237}$

\section{ACKNOWLEDGEMENTS}

The authors deeply appreciate the financial support offered by National Natural Science Foundation of China (Granted No.51146009), International Cooperation and Exchange Program from the Ministry of Science and Technology of China (Grant No. 2011DFA60290), and Novark Technology INC.

\section{NOMENCLATURE}

$\begin{array}{ll}B o & \text { Bond number }\left(=D_{i}\left[g\left(\rho_{l}-\rho_{v}\right) / \sigma\right]^{0.5}\right) \\ C_{p} & \text { Constant specific heat }(\mathrm{J} / \mathrm{kg} \cdot \mathrm{K}) \\ D_{i} & \text { Inner diameter }(\mathrm{mm}) \\ D_{o} & \text { Outer diameter }(\mathrm{mm}) \\ g & \text { Gravitational acceleration }\left(\mathrm{m} / \mathrm{s}^{2}\right) \\ h_{f g} & \text { Latent heat of vaporization }(\mathrm{J} / \mathrm{kg}) \\ \Delta T & \text { Temperature difference between outlet and inlet }\left(=\mathrm{T}_{18}-\mathrm{T}_{17}\right) \\ J a & \text { Jakob Number }\left(=C_{p} \Delta T / h_{f g}\right) \\ L & \text { Heat transfer length }(\mathrm{mm}) \\ L_{e} & \text { Length of evaporation section }(\mathrm{mm}) \\ L_{c} & \text { Length of condensation section }(\mathrm{mm}) \\ L_{a} & \text { Length of adiabatic section }(\mathrm{mm}) \\ S & \text { Heat transfer area }\left(\mathrm{m}^{2}\right) \\ \text { Wa } & \text { Wallis Number }\left(1+\left(\rho_{v} / \rho_{l}\right)^{0.25}\right) \\ Q & \text { Power input }(\mathrm{W}) \\ R & \text { Thermal resistance of OHP }(\square / \mathrm{W}) \\ \text { Greek Symbols } \\ \rho & \text { density }\left(\mathrm{kg} / \mathrm{m}^{3}\right) \\ \sigma & \text { Surface tension }(\mathrm{N} / \mathrm{m}) \\ \text { Subscripts } & \\ c & \text { Condensation section } \\ e & \text { Evaporation section } \\ l & \text { Liquid } \\ v & \text { Vapor }\end{array}$

\section{REFERENCES}

Akachi H., Polášek F., 1996, "Pulsating heat pipes," 5th International Heat Pipe Symposium, Melbourne, Australia, 17-20.

Arslan G., Ozdemir M., 2008, "Correlation to predict heat transfer of an oscillating loop heat pipe consisting of three interconnected columns," Energy Conversion and Management, 49(8), 2337-2344. http://dx.doi.org/10.1016/i.enconman.2008.01.014 
Charoensawan P., Terdtoon P., 2007, "Thermal Performance Correlation of Horizontal Closed-Loop Oscillating Heat Pipes." 9th Electronics Packaging Technology Conference, 906-909.

Dobson R. T., 2004, "Theoretical and experimental modeling of an open oscillatory heat pipe including gravity," International Journal of Thermal Sciences, 43(2), 113-119.

http://dx.doi.org/10.1016/j.ijthermalsci.2003.05.003

Katpradit T., Wongratanaphisan T., Terdtoon, P. Kamonpet P., Polchai A., Akbarzadeh A., 2005, "Correlation to predict heat transfer characteristics of a closed end oscillating heat pipe at critical state," Applied Thermal Engineering, 25(14-15), 2138-2151. http://dx.doi.org/10.1016/j.applthermaleng.2005.01.009

Khandekar S., Cui X., Groll M., 2002, "Thermal Performance Modeling of Pulsating Heat Pipes by Artifical Neutral Network," 11th International Heat Pipe Conference, Moscow, Preprint V2, B2, 1-5

Khandekar S., Charoensawan P., Groll M., Terdtoon P., 2003, "Closed loop pulsating heat pipes: Part B. Visualization and semi-empirical modeling ," Applied Thermal Engineering, 2003, 23(16), 2021-2033. http://dx.doi.org/10.1016/S1359-4311(03)00168-6

Polášek F., Zelko M., 1997, "Thermal control of electronic components by heat pipes and thermosyphons; A historical overview," 10th International Heat Pipe Conference, Stuttgart, Germany, 21-25.
Sakulchangsatjatai P., Terdtoon P., Wongratanaphisan T., Kamonpeta P., Murakami M., 2004, "Operation modeling of closed-end and closedloop oscillating heat pipes at normal operating condition," Applied Thermal Engineering, 24(7), 995-1008. http://dx.doi.org/10.1016/j.applthermaleng.2003.11.006

Shafii M. B., Faghri A., Zhang Y. W., 2002, "Analysis of Heat Transfer in Unlooped and Looped Pulsating Heat pipes," International Journal of Numerical Methods for Heat \& Fluid Flow, 12 (3), 585-609. http://dx.doi.org/10.1108/09615530210434304

Wong T., Tong B. Y., Lim S. M., Ooi K.T., 1999, "Theoretical Modeling of Pulsating Heat Pipe," 11th International Heat Pipe Conference, Tokyo, Japan, 159-163.

Zuo Z. J., North M. T., Wert K. L., 2001, "High Heat Flux Heat Pipes Mechanism for Cooling of Electronics," IEEE Transactions on Components and Packing Technologies, vol.24, no.2, 220-225.

Zhang Y. W., Faghri A., Shafii M. B., 2002, “Analysis of Liquid-vapor Pulsating Flow in a U-shaped Miniature Tube," International Journal of Heat and Mass Transfer, 45 (12), 2501-2508. http://dx.doi.org/10.1016/S0017-9310(01)00348-9 